\title{
Investigation on Proactive Personality Status of the College Students
}

\author{
Bianmei SHI \\ Zhejiang University, Hangzhou, China \\ Taizhou University, Taizhou, China
}

\begin{abstract}
In order to investigate college students' proactive personality status, this paper explored College Students' proactive personality status and characteristics with revised and verified proactive personality scale in Chinese version. Results showed: (1) College students' proactive personality present two-dimensional structure under the Chinese cultural background. (2)The total level of college students proactive personality is general. (3)Gender, grade and major difference were significant in College Students' proactive personality.
\end{abstract}

KEYWORD: College student; Proactive Personality; Investigation

\section{INTRODUCTION}

Affected positive psychology movement, there is an increasing research interest in people's positive psychological qualities or abilities. In the study of the initiative composition of organizational behavior, Bateman and Crant (1993) found that the actions taken had different tendency in changing external environment. This tendency was named as proactive personality. Recent research demonstrates that proactive personality has a positive impact on many organizations and individual personality variables, for example, creativity (innovative, creative performance, innovation behavior), leadership, career success, entrepreneurship. Therefore, it is important significance to investigate the status and influence factors of college students proactive personality status.

\section{RESEARCH METHOD}

\subsection{Research object}

With the method of convenience sampling, participants were college students enrolled in 10 colleges and universities in Zhejiang province. Totally 1000 questionnaires were sent out and 936 valid ones were retrieved. In order to testing scale reliability and validity, questionnaires were randomly divided into two groups 。Sample I (468) was used to revise the scales, sample II (468) was used to verify the revised scale and hypothesis testing.
After deleting the invalid questionnaires of sample I, 400 questionnaires with valid answers were obtained, in which male students $(\mathrm{N}=207)$ account for $51.8 \%$, female students $(\mathrm{N}=193)$ account for $48.2 \%$. Viewed from the grade, Freshmen( $\mathrm{N}=198), \quad$ sophomore $(\mathrm{N}=72)$, junior $(\mathrm{N}=119)$, seniors $(\mathrm{N}=11)$ respectively account for $49.5 \%, 18.0 \%, 29.7 \%, 2.8 \%$. Viewed from the specialty, science and engineering $(\mathrm{N}=242)$, literal arts and humanities $(\mathrm{N}=34)$, economic management speciality $(\mathrm{N}=58)$, art speciality $(\mathrm{N}=10)$, medical specialty $(\mathrm{N}=56)$ respectively account for $60.5 \%$, $8.5 \%, 14.5 \%, 2.5 \%, 14.0 \%$.

\subsection{Research tool}

Considering that proactive personality was put forward relatively late, Bateman's point of view was adopted on the concept of proactive personality basically. This paper adopts Bateman's original proactive personality scale. The scale contains 17 items, one-dimensional structures. The concordance coefficient of the original scale was 0.89 .

\section{RESEARCH RESULTS}

\subsection{Exploratory factor analysis}

Before exploratory factor analysis, we examined relevance of the sample data. KMO index of the scale was 0.883 , Bartlett test of sphericity chi-square was 1780.388, Significant $\mathrm{p}=0.000 \quad(<0.001)$. Therefore, the data was suitable for factor analysis. Exploratory factor analysis was done with by 
principal component analysis and varimax method. The result obtained three factors. The results were shown in table 1 .

Table 1 showed that $\mathrm{Z} 2$ was loaded on the first factor and the second factor, Z13 was loaded on the first factor, the second factorand the third factor, Z6 and Z11 were loaded on the second factor and the third factor, Z5 and Z14 were loaded on the first factor and the third factor. So we deleted Z2, Z5, Z6, Z11, Z13, Z14. Thus, the third factor only contained $\mathrm{Z} 17, \mathrm{Z} 17$ was also deleted. For the remaining nine items, exploratory factor analysis was done again in the same way. The final results were two clear dimensions, $52.945 \%$ contribution rate of variance. According to the significance of items, Z4, Z10, Z15 and Z16 were measured to find out whether people prefer to discover and identify opportunities or capture opportunities. Z1, Z7, Z8, Z9 and Z12 were measured to find out whether people has the desire to change their environment, or change the status quo under adverse conditions through their own active action. Therefore, the first factor was named "insight", the second factor was named "initiative" in this paper.

Table 1.Proactive personality scale rotated component matrix

\begin{tabular}{|c|c|c|c|}
\hline \multicolumn{2}{|c|}{ item } & \multicolumn{2}{c|}{ factor } \\
\hline Z15 & 1 & 2 & 3 \\
\hline Z16 & 0.821 & 0.075 & 0.144 \\
\hline Z4 & 0.605 & 0.125 & 0.053 \\
\hline Z10 & 0.561 & 0.301 & 0.056 \\
\hline Z13 & 0.440 & 0.340 & 0.362 \\
\hline Z9 & 0.043 & 0.705 & 0.058 \\
\hline Z7 & 0.148 & 0.627 & 0.139 \\
\hline Z12 & 0.268 & 0.592 & 0.299 \\
\hline Z8 & -0.022 & 0.531 & 0.243 \\
\hline Z1 & 0.274 & 0.493 & 0.256 \\
\hline Z2 & 0.338 & 0.435 & 0.008 \\
\hline Z17 & 0.215 & -0.083 & 0.724 \\
\hline Z6 & -0.270 & 0.504 & 0.624 \\
\hline Z5 & 0.413 & 0.176 & 0.579 \\
\hline Z11 & 0.232 & 0.360 & 0.536 \\
\hline Z14 & 0.404 & 0.173 & 0.459 \\
\hline
\end{tabular}

\subsection{Confirmatory factor analysis}

According to the results of exploratory factor analysis, using the maximum likelihood estimation method was used for confirmatory factor analysis by the AMOS17.0 software, the proactive personality scale two-dimensional structure standardized model was get under the condition of each path coefficient significant(Figure 1).
The fit index of the proactive personality scale two-dimensional structure model was shown in table 2 . The fit index basically reached the standard values according to the table 2 . So, the two-dimensional structure model of the proactive personality scale showed good fit.

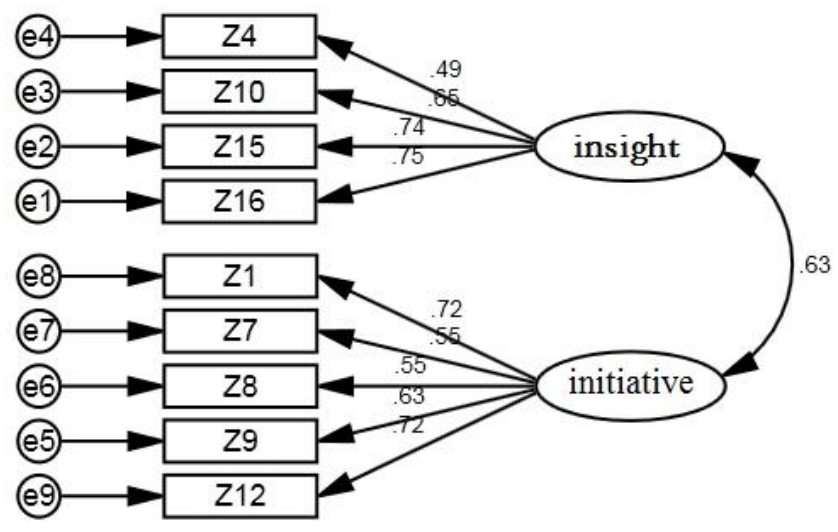

Figure 1 The proactive personality scale two-dimensional structure model

Table 2. The fit index of the two-dimensional structure model of the proactive personality scale

\begin{tabular}{|l|l|l|l|l|l|l|}
\hline fit index & $\chi 2 / \mathrm{df}$ & GFI & AGFI & CFI & RMSEA & RMR \\
\hline two-dimensional & 2.907 & $\begin{array}{l}0.96 \\
1\end{array}$ & 0.932 & 0.951 & 0.069 & 0.024 \\
\hline
\end{tabular}

\subsection{Confidence test}

Internal concordance coefficient (Cronbach $\alpha$ ) was analyzed to verify the reliability of the scale. The reliability test results showed that internal consistency coefficient were respectively as follows: insight 0.748 , initiative 0.771 , proactive personality 0.821 , reliability requirements were satisfied.

\subsection{Demographic characteristics of the college students' proactive personality}

\subsubsection{The total situation of the college students' proactive personality}

The mean value of College students' proactive personality was 2.768. Initiative was more outstanding, the mean value was 3.023. Insight was more generally, the mean value was only 2.513 .

\subsubsection{Gender difference in the college students' proactive personality}

The two dimensions of proactive personality are the dependent variable, and the gender as independent variable was done with sample T-test. The results showed that there were significant gender differences in the college students' proactive personality and its insight and initiative dimensions (see table 3). 
Table 3. gender differences in the college students' proactive personality

\begin{tabular}{|c|c|c|c|c|c|c|}
\hline \multirow{2}{*}{ variable } & \multirow{2}{*}{ gender } & \multirow{2}{*}{ Mean value } & \multicolumn{2}{|c|}{ T-test } & \multicolumn{2}{|c|}{ Levene test } \\
\hline & & & $\mathrm{t}$ & Sig. & $\mathrm{F}$ & Sig. \\
\hline \multirow{2}{*}{ insight } & male & 2.617 & \multirow{2}{*}{3.758} & \multirow{2}{*}{0.000} & \multirow{2}{*}{4.935} & \multirow{2}{*}{0.027} \\
\hline & female & 2.415 & & & & \\
\hline \multirow{2}{*}{ initiative } & male & 3.098 & \multirow{2}{*}{2.940} & \multirow{2}{*}{0.003} & \multirow{2}{*}{0.182} & \multirow{2}{*}{0.670} \\
\hline & female & 2.954 & & & & \\
\hline \multirow{2}{*}{$\begin{array}{l}\text { proactive } \\
\text { personality }\end{array}$} & male & 2.858 & \multirow{2}{*}{3.896} & \multirow{2}{*}{0.000} & \multirow{2}{*}{1.956} & \multirow{2}{*}{0.163} \\
\hline & female & 2.684 & & & & \\
\hline
\end{tabular}

\subsubsection{Grade difference in the college students' proactive personality}

Proactive personality and its two dimensions as the dependent variable, grade as independent variables, the result of single factor analysis of variance showed table 4. There are significant grade differences in the college students' proactive personality and insight dimension, but initiative dimension was no significant differences in grade. Further, using the LSD method for multiple comparison, the sophomore were significantly higher than that of the freshman in proactive personality and insight dimensions.

Table 4. Grade difference in the college students' proactive personality

\begin{tabular}{|c|c|c|c|c|c|c|}
\hline \multirow{2}{*}{ Grade } & \multicolumn{2}{|c|}{ insight } & \multicolumn{2}{c|}{ initiative } & \multicolumn{2}{c|}{$\begin{array}{c}\text { proactive } \\
\text { personality }\end{array}$} \\
\cline { 2 - 7 } & $\begin{array}{c}\text { Mean } \\
\text { value }\end{array}$ & SD & $\begin{array}{c}\text { Mean } \\
\text { value }\end{array}$ & SD & $\begin{array}{c}\text { Mean } \\
\text { value }\end{array}$ & SD \\
\hline Freshmen & 2.444 & 0.553 & 2.998 & 0.513 & 2.721 & 0.466 \\
\hline sophomore & 2.671 & 0.538 & 3.087 & 0.505 & 2.879 & 0.460 \\
\hline junior & 2.550 & 0.492 & 3.033 & 0.436 & 2.791 & 0.382 \\
\hline seniors & 2.750 & 0.559 & 3.088 & 0.401 & 2.919 & 0.421 \\
\hline $\mathrm{F}$ & 4.326 & \multicolumn{2}{|c|}{0.713} & 2.919 \\
\hline $\mathrm{p}$ & \multicolumn{2}{|c|}{0.005} & \multicolumn{2}{c|}{0.545} & \multicolumn{2}{c|}{0.034} \\
\hline
\end{tabular}

\subsubsection{Major difference in the college students' proactive personality}

Proactive personality and its two dimensions as the dependent variable, major as independent variables, the result of single factor analysis of variance showed table 5. There were significant major differences in the college students' proactive personality and its two dimensions.
Table 5. Major difference in the college students' proactive personality

\begin{tabular}{|l|l|l|l|l|l|l|}
\hline major & \multicolumn{2}{|l|}{ insight } & \multicolumn{2}{l|}{ initiative } & \multicolumn{2}{l|}{$\begin{array}{l}\text { proactive } \\
\text { personality }\end{array}$} \\
\hline & $\begin{array}{l}\text { Mean } \\
\text { value }\end{array}$ & SD & $\begin{array}{l}\text { Mean } \\
\text { value }\end{array}$ & SD & $\begin{array}{l}\text { Mean } \\
\text { value }\end{array}$ & SD \\
\hline $\begin{array}{l}\text { Science and } \\
\text { engineering }\end{array}$ & 2.523 & 0.551 & 3.053 & 0.468 & 2.788 & 0.432 \\
\hline Literal arts & 2.569 & 0.537 & 3.048 & 0.538 & 2.808 & 0.485 \\
\hline $\begin{array}{l}\text { Economic } \\
\text { management }\end{array}$ & 2.609 & 0.538 & 3.070 & 0.540 & 2.839 & 0.467 \\
\hline Art specialty & 2.900 & 0.474 & 3.360 & 0.397 & 3.130 & 0.356 \\
\hline Medical & 2.226 & 0.462 & 2.750 & 0.456 & 2.488 & 0.411 \\
\hline F & 5.682 & & 5.688 & & 7.545 & \\
\hline $\mathrm{p}$ & 0.000 & & 0.000 & & 0.000 & \\
\hline
\end{tabular}

Further, using the LSD method for multiple comparison, the medical specialty was significantly lower than that of the science and engineering, literal arts and humanities, economic management speciality in proactive personality and its two dimensions. The art speciality was significantly higher than that of the science and engineering, literal arts and medical specialty in proactive personality, and significantly higher than that of the science and engineering and medical specialty in insight, and significantly higher than that of the medical specialty in initiative.

\section{ANALYSIS AND DISCUSSION}

\subsection{The whole level of college students' proactive personality is low}

The research results showed that the whole level of college students' proactive personality was low, the proactive personality level of only $47.4 \%$ college students was higher than the average in the proactive personality level. This showed that the whole level of college students' proactive personality was low. The scored was higher in initiative dimensions of proactive personality. It showed that college students are easy to accept new things, new ideas, new knowledge, new things, dare to change, with a strong pioneering spirit of innovation. However, the scored was lower in insight dimensions of proactive personality. It showed that, because of shortage of college students' knowledge reserve and experience, the ability of searching, identifying and capturing opportunities and actively create conditions and opportunities to change the environment are insufficient.

\subsection{Gender difference in the college students' proactive personality}

The results showed that there were significant gender differences in the college students' proactive personality. The level of men's proactive personality, 
insight and initiative dimensions was significantly higher than that of women's. The reason may be that male and female social role expectation is different. Social culture is looking forward to male more social responsibility, and active, creative and pioneering role. Social expect prompts male to develop by self expectation, self adjusting. Thus, they have more contact with pioneering transactions in social affairs. They need more active and harder to control and change the surrounding environment. Therefore, the proactive personality of male is significantly higher than that of female. On the contrary, social expectations of female is not high in the same respects. Female who do more routine affairs are accepted by Social culture. So, the reason why initiative level of male was higher than that of female correspondingly is that the requirements of traditional roles to gender is different.

\subsection{Grade difference in the college students' proactive personality}

The results showed that there are significant grade differences in the college students' proactive personality. Students' proactive personality gradually increased in the freshman and sophomore year, in the junior year gradually declined, and increased again and up to a peak in the senior year. Further, using the LSD method for multiple comparison, the results were shown that the sophomore were significantly higher than that of the freshman in proactive personality and insight dimensions. The reason may be that, relative to college life, the way of middle school life was more passive and stylized. The freshman needed to adapt in a period of time. After a year of time to adapt, and interact with the environment, when entered the sophomore year, most students had begun to adapt to college life. So the sophomore began to more proactive approach to learn and live. Once college students completely adapted to college life in the freshman and sophomore year, their motivation began to drop, college students' proactive personality and its two dimensions were thereupon gradually decline. In the senior stage, under pressure from employment and graduate examination, students' work enthusiasm, initiative and purpose began to rise, the levels of proactive personality and its two dimensions gradually strengthened. The fluctuation phenomena of proactive personality in college period showed that college students' proactive personality was unstable and may changed with the change of age and experience. The reason may be that college students are in a period of psychological developing and perfecting constantly. Therefore, they showed the self-cognition is in an unstable state.

\subsection{Major difference in the college students' proactive personality}

The results showed that there were significant major differences in the college students' proactive personality. The level of art specialty students' proactive personality and its two dimensions was the highest. The following rankings were respectively economic management specialty, literal arts, science and engineering and medical specialty. Further, using the LSD method for multiple comparison, the results showned that the level of science and engineering, literal arts, economic management specialty students' proactive personality were significantly higher than that of the medical specialty students. Art specialty students' proactive personality were significantly higher than that of the science and engineering, literal arts and medical specialty students. The cause of this result may be that the way of thinking were different in different mayors. For the thinking mode of students in science and engineering and medical majors, was more rational, logical. In the college, it was difficult to most science and engineering and medical specialty students that the difficulty and quantity of science knowledge increased greatly. Many college students still continued to use learning methods in secondary school, so much so that they couldn't adapt to college life and exhibit disoriented and reducing enthusiasm in initiative of the learning. The knowledge of art, economic management and liberal arts specialty were not so difficult relatively. In other words, the liberal arts learning was a kind of thought or idea that was relatively more divergent and development. So the liberal arts students were good at using dialectical thinking methods. Therefore, they were more likely to adapt to college learning, also easier to find and seize the opportunities, and more proactive to school or activities than science and engineering and medical specialty students.

\section{REFERENCES}

[1] Bateman,T.S., \& Crant,J.M.. The proactive component of organizational behavior: A measure and correlates. Journal of Organizational Behavior, 1993, 14(2): 103-118.

[2] Seibert, S.E., \& Crant,J.M., \& Kraime, M.L.. Proactive personality and career sueeess. Journal of Applied Psychology, 1999, 84(3): 416-427.

[3] Kim, T.Y., Hon, A.H.Y., \& Grant, J.M.. Proactive Personality, Employee Creativity, and Newcomer Outcomes: A Longitudinal Study. Journal of Businsess Psychology, 2009, 24: 93-103.

[4] Grant J M. The proactive personality scale and objective job performance among real estate agents. Journal of Applied Psychology, 1995, 80:532-537

[5] Seibert, S.E., \& Kraimer, M.L., \& Crant, J.M.. What do proactive people do? A longitudinal model linking proactive personality and career success. Personnel Psychology, 2001, 54(4): 845-874.

[6] Thompson, J.A.. Proactive personality and job performance: A social capital perspective. Journal of Applied Psychology, 2005, 90(5): 1011-1017. 